\title{
Responsiveness of human monocytes to the commensal bacterium Staphylococcus epidermidis develops late in gestation
}

\author{
Tobias Strunk 1 , Amy Prosser ${ }^{2}$, Ofer Levy ${ }^{3}$, Victoria Philbin ${ }^{3}$, Karen Simmer', Dorota Doherty ${ }^{4}$, Adrian Charles ${ }^{4}$, Peter Richmond ${ }^{2}$, \\ David Burgner ${ }^{5}$, Andrew Currie ${ }^{6}$
}

INTRODUCTION: Staphylococcus epidermidis (SE) rarely causes infection in term infants but is a leading cause of lateonset sepsis in preterm infants. We hypothesized that the innate immune responses to $\mathrm{SE}$ in preterm infants are impaired in a gestational age (GA)-dependent manner.

METHODS: Cord and peripheral blood mononuclear cells (MNCs) were stimulated with SE bacteria, and a range of innate immune responses were assessed, including phagocytosis, intracellular killing, Toll-like receptor (TLR) pathway transcriptional activation, cytokine production, TLR2 and TLR4 expression, and cell signaling.

RESULTS: Phagocytosis and intracellular killing of SE bacteria were similar in neonatal and adult monocytes. Cytokine gene expression and protein synthesis increased in a GA-dependent manner, which was confirmed at the single-cell level. These GA-related effects were not associated with differences in expression of TLR2 or TLR4, nor with downstream activation of nuclear factor-kB or mitogen-activated protein kinase pathways.

DISCUSSION: The expression of TLRs, phagocytic capacity, and intracellular killing by monocytes develops early in fetal development, whereas the ability to mount a bacteria-induced cytokine response requires further maturation. The functional immaturity of monocyte activation pathways in the preterm infant may underpin their particular susceptibility to sepsis with commensal bacteria.

$S^{t}$ aphylococcus epidermidis (SE), a ubiquitous commensal bacterium of the skin and mucous membranes, is responsible for $\sim 50 \%$ of all late-onset neonatal septicemia $(1,2)$. Extremely preterm infants $(<30 \mathrm{wk}$ gestational age $(\mathrm{GA}))$ are uniquely susceptible to SE infection, with 10-60\% experiencing at least one episode (3). Although direct mortality from SE infection is lower than that from less common gram-negative bacteria and fungi (4-7), SE septicemia is associated with an increased risk of common adverse outcomes, prolonged hospital stay, and increased costs (8-12). The immunologic mechanisms underlying this increased susceptibility of preterm infants to $\mathrm{SE}$ infections are poorly understood but are important in developing effective preventive and therapeutic interventions.

Preterm infants have relatively deficient innate immunity, including impaired phagocytosis, intracellular killing, and cytokine production. However, most of the available data are from studies using pathogens causing early-onset sepsis or purified agonists such as lipopolysaccharide (LPS) (13-17). The responses of the developing innate immune system to SE have received less attention $(18,19)$. The interactions between SE and monocytes, which are central to early innate immune responses and an essential link to adaptive immunity, are likely to be of particular importance (19).

Here we report that human preterm monocytes exposed to SE bacteria have normal levels of Toll-like receptor (TLR) expression, phagocytic capacity, and intracellular killing but reduced numbers of cytokine-producing monocytes, resulting in broadly impaired cytokine transcription and translation. These defects may contribute to the particular susceptibility of preterm infants to SE infection.

\section{RESULTS}

SE-Induced TLR-Pathway Gene Expression Is Dependent on GA We characterized the expression of neonatal and adult TLRpathway related genes in response to in vitro stimulation of mononuclear cells (MNCs) with heat-killed SE (HKSE) (Figure 1a-d). Direct comparison of gene expression patterns between the groups demonstrated that both the number of upregulated genes and the degree of upregulation were significantly lower in the most premature infants as compared with moderately preterm infants, term infants, and adults.

\section{GA-Dependent Impairment of Cytokine Production in Response} to SE

We selected key cytokines from the reverse transcription PCR array for further comparative analysis of the responses to $\mathrm{SE}$, and consistently found the lowest messenger RNA (mRNA) expression levels in the infants born at the lowest GA (Figure 2a) $(n=5$ 


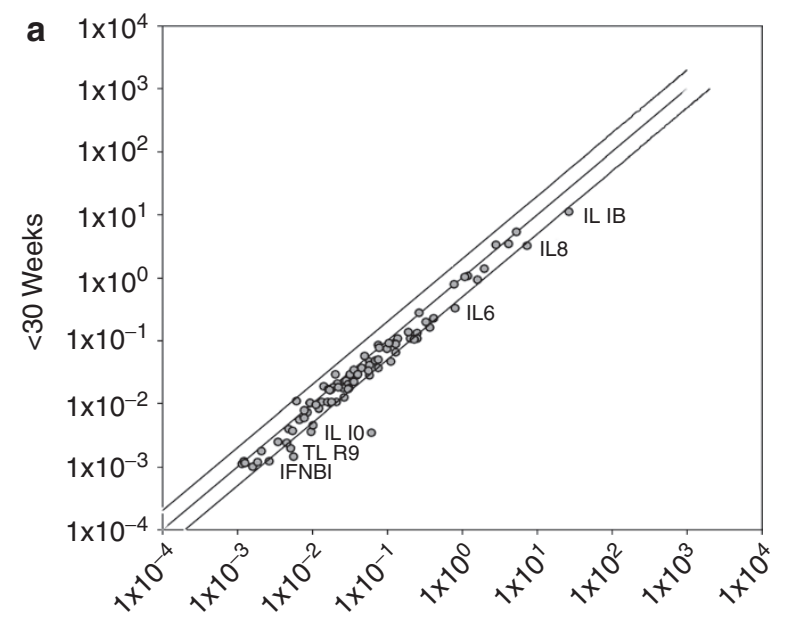

31-33 Weeks

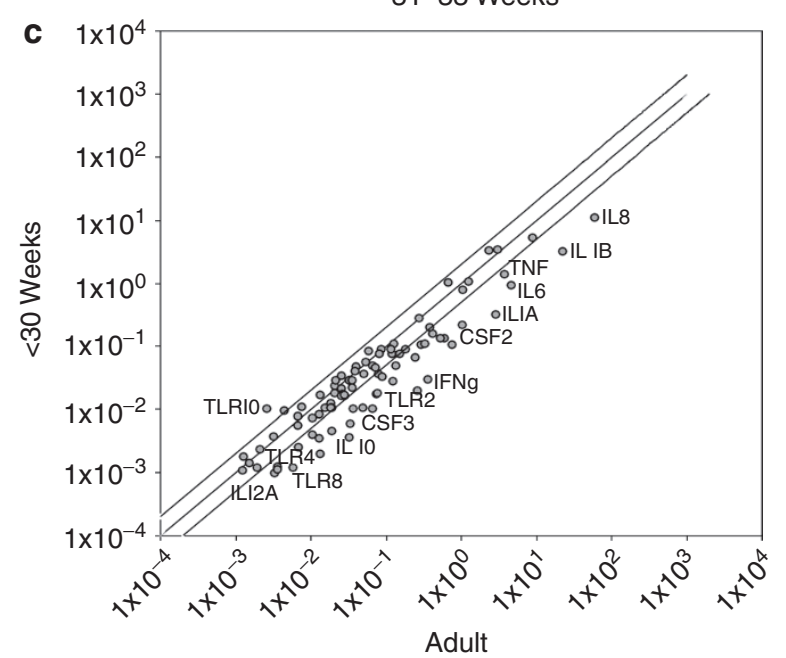

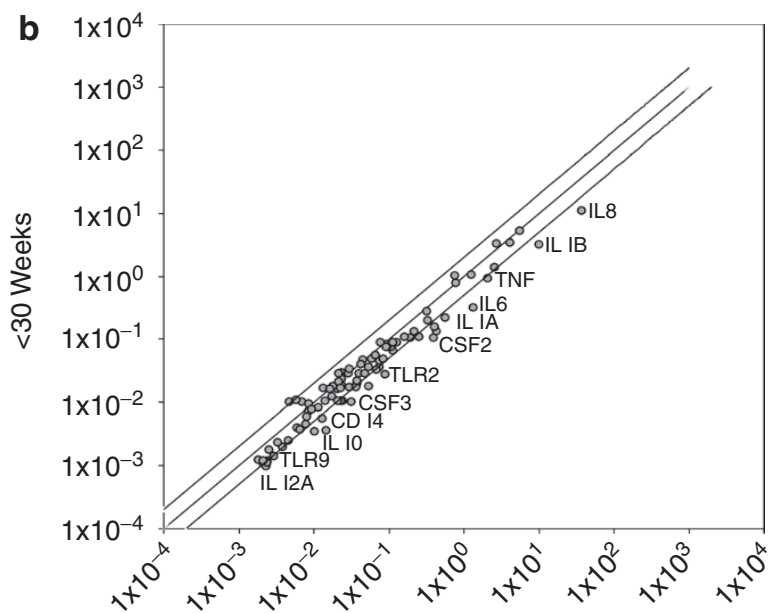

37-41 Weeks

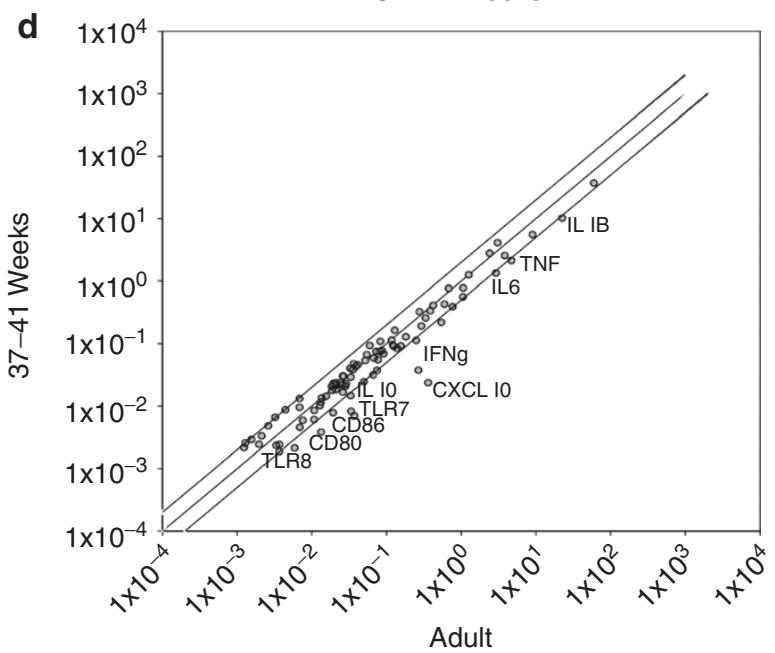

Figure 1. TLR-pathway associated gene expression in response to Staphylococcus epidermidis. (a-d) Log transformation plots of SE-stimulated gene expression among preterm, term, and adult MNCs ( $n=5$ in each group). Central lines indicate equivalence; outer lines indicate a twofold difference in gene expression. CXCL, chemokine CXC motif ligand; IFN, interferon; IL, interleukin; MNC, mononuclear cell; SE, Staphylococcus epidermidis; TLR, Toll-like receptor; TNF, tumor necrosis factor.

per group). Furthermore, there was a proportional increase in gene expression levels with increasing GA $\left(P=0.01, r^{2}=0.41\right.$ for interleukin (IL) $1 \beta ; P=0.005, r^{2}=0.47$ for IL6; $P=0.007, r^{2}=$ 0.44 for IL8; $P=0.014, r^{2}=0.38$ for IL10; and $P=0.04, r^{2}=0.28$ for tumor necrosis factor (TNF)- $\alpha$ ).

We then determined cytokine protein concentrations in MNC culture supernatants. The concentration levels of SE-induced IL1 $\beta$, IL6, IL8, and TNF- $\alpha$ in MNCs of infants with very low GA were significantly lower as compared with those in adults (Figure 2b). In moderately preterm infants, significantly lower levels of IL1 $\beta$, IL6, and TNF- $\alpha$ were seen relative to values in adults. In term infants, with the exception of TNF- $\alpha$ levels, which were lower than in adults, the levels did not differ significantly from those in adults. Linear regression analysis revealed significant increases in cytokine responses with increasing GA with respect to IL6 $(n=45$, $\left.r^{2}=0.25, P=0.005\right)$, TNF- $\alpha\left(n=37, r^{2}=0.19, P=0.007\right)$, and IL8 $\left(n=15, r^{2}=0.26, P=0.05\right)$, and a similar trend for IL1 $\beta$ $\left(n=15, r^{2}=0.22, P=0.08\right)$.

\section{Activation of Monocytes by SE Is GA-Dependent and Requires Phagocytosis}

We investigated the cellular source of SE-specific cytokine responses and assessed whether reduced gene expression results from a decrease in the number of cytokine-producing cells and/ or reduced expression of cytokine per cell (Figure 3). We u sed a method recently developed by our laboratory that allows for reliable simultaneous detection of intra-phagolysosomal bacteria and intracellular cytokine content (17). Monocytes were found to be the sole source of TNF and IL-6 in all the groups tested (data not shown). There was an overall GA-dependent response; both the total number of cytokine-producing monocytes and the cytokine production per cell were significantly lower in infants with the lowest GA as compared with adults (Figure 3a,b).

Flow cytometry revealed that only monocytes that were positive for intracellular SE produced IL6 and TNF- $\alpha$, suggesting that phagocytosis was an absolute requirement for cytokine induction. However, not all phagocytic cells produced cytokines (Figure 3c,d). 

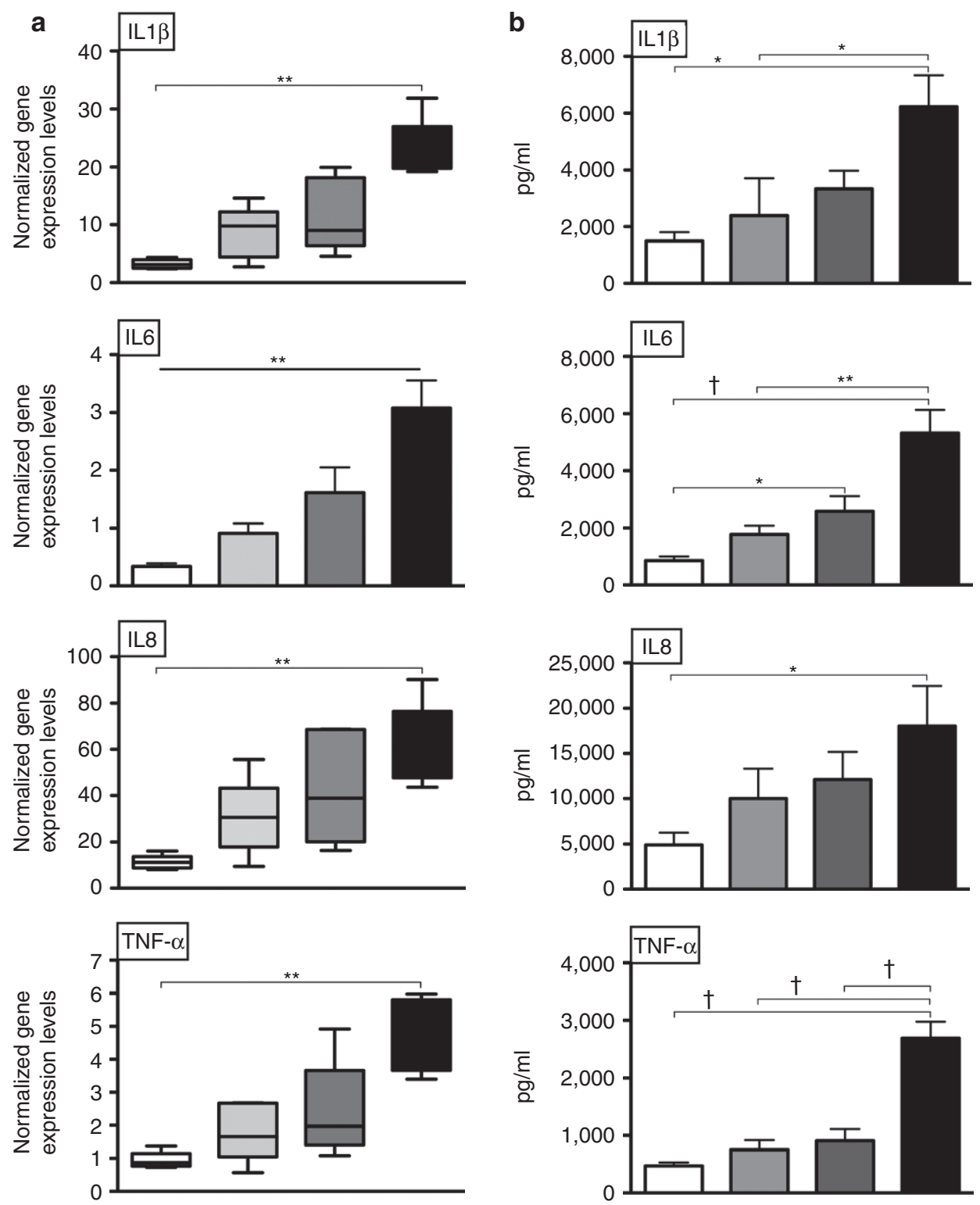

Figure 2. Cytokine expression in response to Staphylococcus epidermidis in neonatal MNCs. (a) Cytokine gene expression in response to stimulation with Staphylococcus epidermidis in MNCs of extremely preterm (<30 wk GA, white), moderately preterm (31-33 wk GA, light gray), and term infants (37-41 wk $\mathrm{GA}$, dark gray) in comparison to adults ( $n=5 /$ group). Data are presented as mean $\pm \mathrm{SEM},{ }^{*} P<0.05,{ }^{* *} P<0.01,+{ }^{+} P<0.001$. (b) Production of cytokine protein after stimulation with Staphylococcus epidermidis by neonatal and adult MNCs. Graphs show mean \pm SEM (IL6, TNF- $a, n=14-20$ per group; IL1 $\beta$, IL8, $n$ $=4-6$ per group). ${ }^{*} P<0.05,{ }^{*} P<0.01,{ }^{\dagger} P<0.001 . \mathrm{GA}$, gestational age; IL, interleukin; MNC, mononuclear cell; TNF, tumor necrosis factor.

Phagocytic and Intracellular Killing Capacity of Monocytes Is GA-Independent

To determine whether the differences in cytokine production observed were attributable to reduced bacterial uptake by monocytes in preterm infants, we examined the kinetics of nonopsonic and opsonic phagocytosis. We found similar kinetics and phagocytic indexes in all the groups (Figure 4a). Furthermore, opsonization of SE with rabbit serum significantly and equivalently increased the uptake of SE bacteria by monocytes in all groups (Figure 4 b).

Given that the uptake of SE bacteria is equivalent in neonatal monocytes and in adult monocytes, we investigated the ability of neonatal monocytes to control in vitro infection with live SE bacteria. Employing a recently described method for assessment of intracellular killing capacity (20), we observed similar efficiency in killing of bacteria in all the GA groups, with $<0.01 \%$ of the original number of SE bacteria remaining viable after $1 \mathrm{~h}$ of incubation with MNCs (Figure 5).

\section{Monocyte Surface Expression of TLRs}

To investigate the differential expressions of innate immune receptors potentially involved in the recognition of SE, we analyzed mRNA and protein expression of TLRs. There were no 

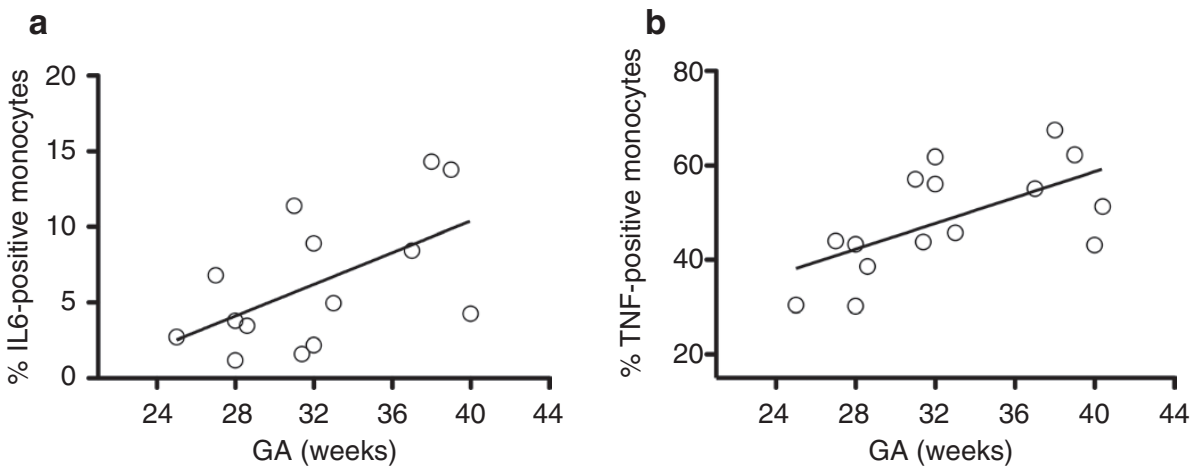

C

d
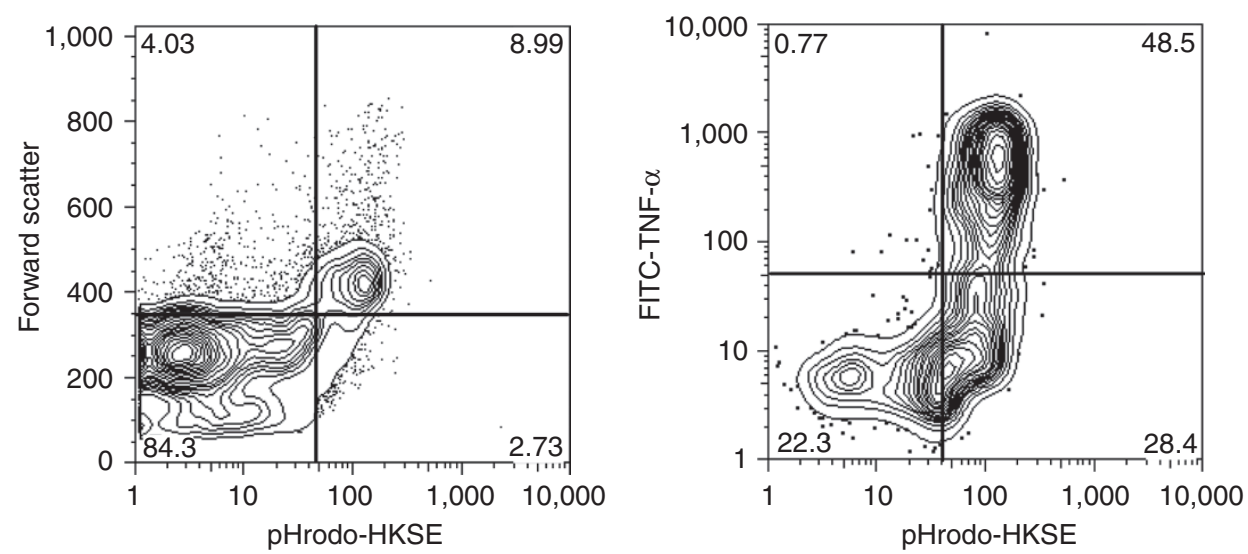

Figure 3. GA-dependent maturation of heat-killed SE-induced intracellular cytokine production. (a,b) Percentage of IL6-and TNF-a-positive monocytes according to GA, respectively (a: $\left.r^{2}=0.32, P<0.05 ; \mathbf{b}: r^{2}=0.38, P<0.05\right)(n=5 /$ group). Representative flow cytometry plots demonstrate (c) the percentage of monocytes that phagocytose pHrodo-labeled SE bacteria and (d) the percentage of pHrodo-positive monocytes that produce TNF-a. GA, gestational age; FITC, fluorescein isothiocyanate; HKSE, heat-killed Staphylococcus epidermidis; IL, interleukin; SE, Staphylococcus epidermidis; TNF, tumor necrosis factor.

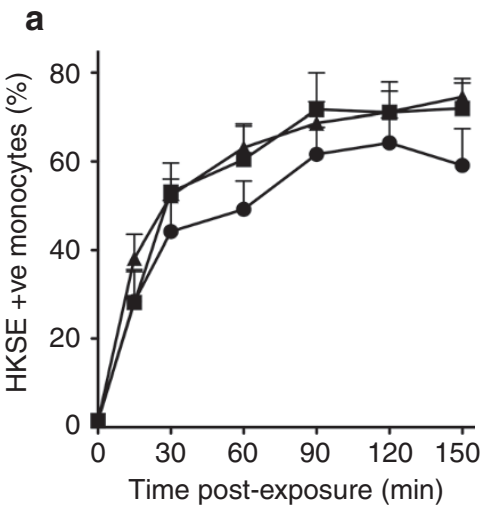

b

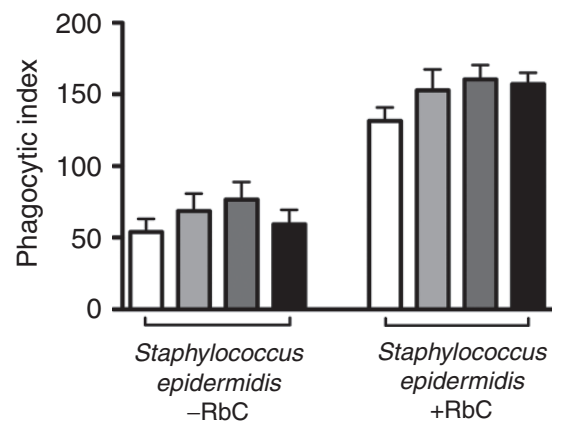

Figure 4. Equivalent phagocytosis of heat-killed SE by neonatal and adult mononuclear cells. (a) Kinetics of uptake of pHrodo-labeled SE (HKSE +ve) in extremely preterm (circles) and term infants (squares) as compared with adults (triangles) ( $n=5 /$ group). (b) Phagocytic index of monocytes of extremely preterm ( $<30 \mathrm{wk} \mathrm{GA}$, white), moderately preterm (31-33 wk GA, light gray), and term infants (37-41 wk GA, dark gray) in comparison to adults (black) ( $n=$ 5/group). Graphs show mean \pm SEM. GA, gestational age; HKSE, heat-killed Staphylococcus epidermidis; SE, Staphylococcus epidermidis.

significant differences in gene expressions of TLR2, TLR4, or TLR6 between preterm infants and term neonates (Figure 6a-c). We next determined the expression levels of TLR2 and TLR4 proteins on monocytes, using flow cytometry (Figure 6d,e). We observed a trend toward increasing numbers of TLR4-positive monocytes with increasing GA; however, this association was not statistically significant. Furthermore, we did not find differences between the GA groups in the median fluorescence intensities of either the TLR2-positive or the TLR4-positive monocytes.

We next examined the downstream signaling events associated with TLR-dependent activation. We found that the numbers of phospho-p65-positive, phospho-p38-positive, and JNK-positive monocytes after stimulation with SE were similar among the groups (Figure 7). 


\section{DISCUSSION}

We have demonstrated that, even in extremely preterm infants, SE is efficiently phagocytosed, but that subsequent activation of innate immune responses is significantly impaired. It is likely that these GA-related deficiencies contribute to the heightened susceptibility of extremely premature infants to SE infection.

Early-response cytokines (IL1 $\beta$, IL6, IL8, and TNF- $\alpha$ ) are initiated by activation of nuclear factor- $\kappa \mathrm{B}$ (16). In keeping

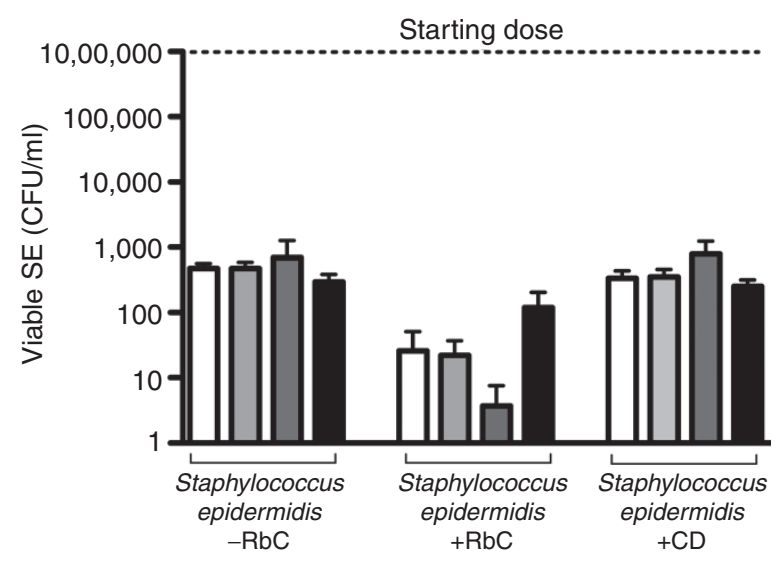

Figure 5. Similar intracellular killing capacity of neonatal and adult mononuclear cells. Capacity of intracellular killing by mononuclear cells in extremely preterm ( $<30 w k \mathrm{GA}$, white), moderately preterm (31-33 wk GA, light gray), and term infants (37-41 wk GA, dark gray), and adults (black) ( $n=5 /$ group). The logarithmic graph shows the mean number of viable SE bacteria $/ \mathrm{ml} \pm \mathrm{SEM}$ in relation to the inoculated number of bacteria (starting dose) in the presence/absence of baby rabbit complement $(\mathrm{RbC})$ and cytochalasin D (CD). CFU, colony-forming units; GA, gestational age; $S E$, Staphylococcus epidermidis. with the limited data on SE responses in preterm infants (19), our results indicate a significant GA-dependent deficiency in cytokine production by neonatal MNCs after SE stimulation. This was evident at both the transcriptional and translation levels. This finding suggests a profound impairment in the innate inflammatory response to SE in preterm infants.

The clinical correlates of GA-related differences in innate responses to SE are increasingly being recognized. Erythema toxicum neonatorum, which manifests as rash and fever in term neonates $(21,22)$ is thought to result from a inflammatory response to SE bacteria that penetrate the dermis via hair shafts (23). Furthermore, IL6 levels significantly increase during the first weeks of life in noninfected term neonates, possibly reflecting immune recognition of initial colonization with commensal bacteria such as SE (24). Although all neonates are ubiquitously colonized with SE within days after birth (18), erythema toxicum neonatorum is exceptionally rare in preterm infants (21), suggesting significant GA-related differences in innate immune responses in vivo. Furthermore, although term infants rarely develop invasive SE infection, this organism represents the most common cause of late-onset septicemia in preterm infants (4).

Engagement of phagocyte surface receptors, phagocytosis, and intracellular bacterial killing are key to the initial innate immune response. Phagocytosis and intracellular killing by neonatal monocytes are comparable to those achieved by adult MNCs (25-29). However, these data are derived from stimulation studies using early-onset sepsis pathogens or latex particles; there are no analogous data on phagocytosis of SE by monocytes in preterm infants. Our results are the first

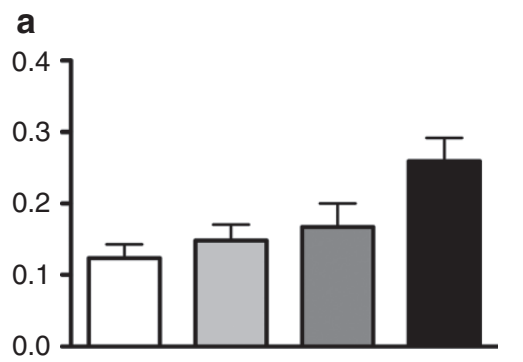

d

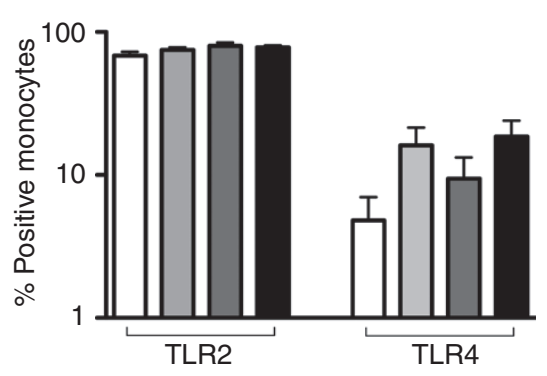

b

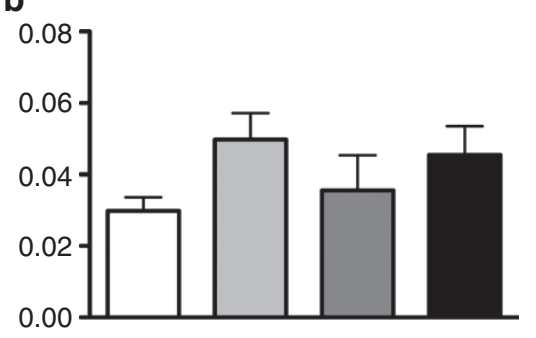

e
C

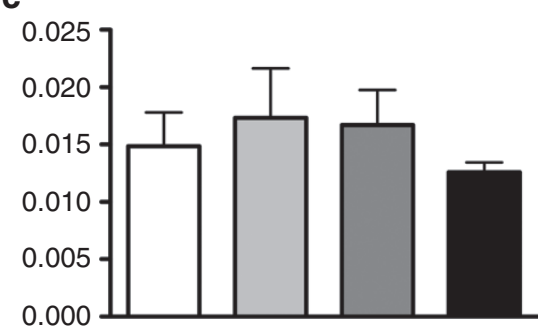

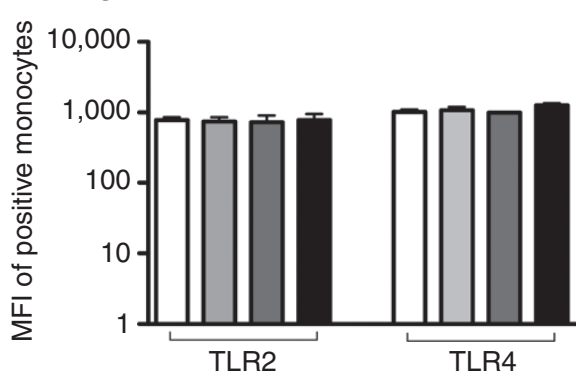

Figure 6. Neonatal and adult mononuclear cells express similar amounts of TLR2, TLR4, and TLR6. (a-c) Mean normalized gene expression levels \pm SEM of TLR2, TLR4, and TLR6, respectively, in extremely preterm ( $<30 \mathrm{wk} \mathrm{GA}$, white), moderately preterm (31-33 wk GA, light gray), and term infants (37-41 wk GA, dark gray), and adults (black) ( $n=5$ /group). Monocyte surface expression of TLR2 and TLR4. (d) The number of monocytes positive for TLR2 and TLR4, and (e) shows the specific median fluorescence intensity (MFI) of TLR-positive monocytes in extremely preterm ( $<30$ wk GA, white), moderately preterm (31-33 wk GA, light gray), and term infants (37-41 wk GA, dark gray), and adults (black) ( $n=5 /$ group). Positive TLR expression was defined by a fluorescence signal greater than matching isotype control for each donor. Data are presented as mean \pm SEM. GA, gestational age; TLR, Toll-like receptor. 

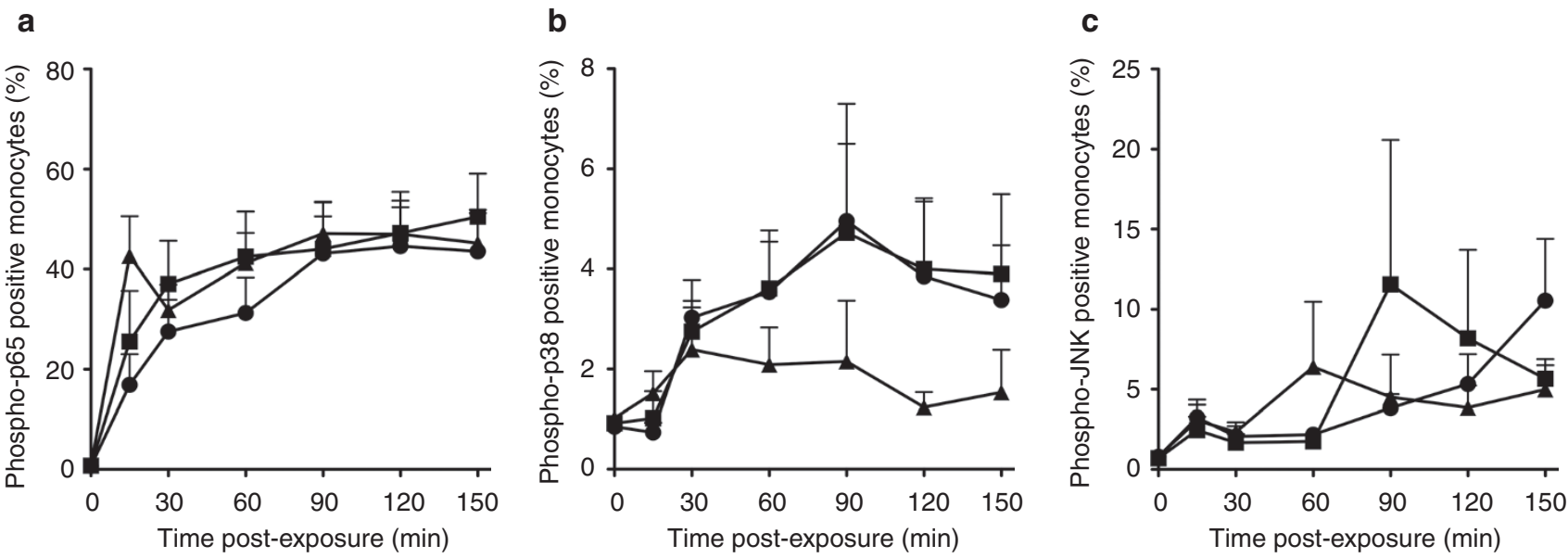

Figure 7. Cell signaling in response to Staphylococcus epidermidis (SE). (a-c) Depict the percentage of monocytes positive for p65, p38, and JNK according to time post-exposure to SE in extremely preterm (circles) and term infants (squares) in comparison to adults (triangles) $(n=5 / g r o u p)$. Data are presented as mean \pm SEM.

to demonstrate similar phagocytic capacities of monocytes (percentage of SE-phagocytosing monocytes and number of ingested bacteria) in preterm neonates, mature neonates, and adults. Crucially, the induction of TNF- $\alpha$ and IL6 was observed only in monocytes containing ingested SE bacteria, irrespective of GA. Furthermore, the MNCs of preterm infants were able to counter in vitro infection with live SE bacteria as effectively as those of term infants and adults.

Given that preterm infants are commonly hypocomplementemic, we assessed monocyte phagocytosis of SE bacteria in the absence and presence of complement. Although opsonization resulted in increased efficiency of bacterial uptake in all groups, it failed to normalize cytokine production by monocytes of infants with very low GA. Furthermore, there was no difference in the numbers of phospho-p65positive monocytes in preterm infants as compared with term infants and adults. Therefore the marked reductions in cytokine levels that are seen in preterm infants in response to SE are not the result of insufficient uptake or intracellular killing of the bacteria or from reduced activation of secondary phosphokinases. The defect that results in reduced phagocytosis-induced cytokine responses in infants with very low GA may reflect distinct features of neonatal signaling pathways that blunt cytokine production. Examples of these are relatively high neonatal plasma concentrations of immunomodulatory adenosine and relatively high concentrations of cyclic adenosine monophosphate in MNCs, or other impairments that may lie downstream of nuclear factor- $\kappa \mathrm{B}$ activation (30). Of note, we were able to detect some cytokine production in response to SE even in extremely premature infants, further indicating that the MNCs of preterm infants are able to recognize and engage SE bacteria. This is in keeping with the clinical observation of raised concentrations of C-reactive protein (which is transcriptionally regulated by IL6) in SE sepsis in very premature infants $(31,32)$.

We have previously shown that SE bacteria engage the innate immune system through TLR2-dependent as well as
TLR2-independent signaling (33). We next examined the expressions of TLR2 and TLR4 in neonatal MNCs (34), both at the mRNA and cell surface protein levels. The monocytes of preterm infants showed abundant TLR2 expression, similar to that in term infants and adults. TLR4 was expressed on a smaller subset of monocytes in preterm infants, but the expression was also equivalent across groups. Similar levels of mRNA and of protein expressions of TLR2 and TLR4 are reported in neonatal cells of term infants and in adult cells (35), whereas another study found that TLR4 expression increased with increasing GA (36). We conclude that differences in responses to SE in preterm infants are unlikely to result from GA-related increases in TLR2 expression.

In summary, our findings represent the most comprehensive assessment of innate immune responses to SE in infants to date. We demonstrate that monocytes from infants born early in gestation express TLR2 and TLR4 at levels similar to those in adults, and that they phagocytose and kill SE bacteria to an extent comparable to those of monocytes of term infants and adults. However, this is not reflected in the form of mature cytokine responses, despite appropriate activation of phosphop65. Delineation of the maturational steps necessary for completely engaging transcriptional activation of cytokine and other genes will be important in developing diagnostic, preventive, and therapeutic strategies to reduce the infectious disease burden in highly susceptible populations such as preterm infants. In addition to in vitro experiments utilizing sophisticated techniques in isolated cells, it will be essential to investigate the complex innate immune responses to SE infection in vivo.

\section{METHODS}

Blood Sampling and Preparation

Cord blood and placental samples were prospectively collected as described earlier $(17,37)$. The human research ethics committee of Princess Margaret and King Edward Memorial Hospitals approved the study, and written informed consent was obtained from all participants. The histology of extraplacental membranes, umbilical cord, chorionic plate, and placenta was examined (38), and only MNCs from pregnancies without chorioamnionitis were used. 
Cord blood was collected from cord vessels and placental surface immediately after delivery, after cleaning with an alcohol swab. Neonates were divided into three groups, corresponding to GA-related risk of bacterial infection (39): (i) very preterm infants, $<30$ wk GA, (ii) moderately preterm infants, $31-33 \mathrm{wk}$ GA and (iii) term, 37-41 wk GA. The total leukocyte and monocyte counts for the groups were similar on manual differential examination. Control blood samples were collected from healthy nonpregnant adults by venipuncture.

Blood samples were mixed 1:1 with heparinized RPMI 1640 culture medium (Gibco, Paisley, Scotland). MNCs were isolated by lymphoprep gradient centrifugation (Nycomed Pharmacia, Elverum, Norway) and cryopreserved using an established method that does not significantly affect cell viability or function (40). For all the experiments, equal numbers from all age groups were batch-analyzed to reduce experimental variation.

\section{Bacterial Culture}

SE strain 1457, an invasive clinical isolate, provided by Dr Michael Otto (National Institute of Allergy and Infectious Diseases, MT), was grown to mid-log phase in brain-heart infusion broth (PathWest, Perth, Western Australia) (41). Bacteria were heat-killed for $15 \mathrm{~min}$ at $80^{\circ} \mathrm{C}$, then washed and resuspended in sterile phosphate-buffered saline (PBS) at $2.5 \times 10^{9}$ colony-forming units (CFU)/ml; the aliquots were stored at $-20^{\circ} \mathrm{C}$. Lack of viability was confirmed by plating serial dilutions of bacterial suspensions onto blood agar. The presence of LPS contamination of SE preparations was excluded by means of Limulus amoebocyte lysate assay (Associates of Cape Cod, East Falmouth, MA) and by lack of response of TLR4-transfected HEK293 cells (Invivogen, San Diego, CA).

\section{MNC Cultures}

Cryopreserved MNCs were thawed rapidly at $37^{\circ} \mathrm{C}$, resuspended in RPMI 1640, centrifuged, and resuspended to a total volume (vol) of $1 \mathrm{ml}$ in AIM-V (Gibco) supplemented with 2-mercaptoethanol (2-ME, Sigma, Sydney, Australia), as described (42). Experimental conditions were optimized for bacterial dose and time of cytokine production, using MNCs from all age groups. The MNCs were counted and cultured at $10^{6}$ live cells/ml in RPMI 1640 with $10 \%$ fetal calf serum in polypropylene 96-well plates (Corning, Corning, NY). SE bacteria were added at indicated final concentrations and the cell cultures were incubated at $37^{\circ} \mathrm{C} / 5 \% \mathrm{CO}_{2}$. Culture supernatants were harvested and stored at $-80^{\circ} \mathrm{C}$ until batch analysis.

\section{TLR-Pathway Gene Expression Array}

Mononuclear pellets from cultures stimulated with SE bacteria at $10^{8} / \mathrm{ml}$ for $6 \mathrm{~h}$ were resuspended and stored in RNAprotect Cell Reagent (Qiagen, Doncaster, Australia) at $--80^{\circ} \mathrm{C}$ until RNA isolation. Cellular lysates were prepared using a QIAshreddar spin column (Qiagen) and total RNA was isolated using the RNeasy kit (Qiagen). From each sample, $50 \mathrm{ng}$ of RNA was then transcribed into CDNA using the reverse transcription PCR array First Strand Kit (SA Biosciences, Frederick, MD) and analyzed on the human TLR-pathway array (SA Biosciences) using the real-time SYBR green/fluorescein PCR master mix (SA Biosciences). Reverse transcription PCR was performed on an ABI Prism 7000 (ABI, Foster City, CA) per the manufacturer's instructions. Gene expression was normalized using multiple housekeeping genes and the data were analyzed using the $\Delta \Delta \mathrm{C}_{\mathrm{t}}$ method (43). The multiple of change in gene expression was calculated in SE-stimulated cells with reference to unstimulated cells.

\section{Cytokine Assays}

Cytokines were measured using commercial enzyme-linked immunosorbent assay (for IL1 $\beta$, IL8; eBioscience, San Diego, CA) or in-house time-resolved fluorometry assay (for IL6, IL10, TNF- $\alpha$ ) in accordance with the manufacturer's instructions or established protocols (42).

Flow Cytometry of Surface Expression of TLR2 and TLR4, Phagocytosis, and Intracellular Cytokines

After thawing, the MNCs were used directly (for basal expression of TLRs) or cultured for analysis of phagocytic capacity and cytokine induction, as described earlier in this paper. For TLR staining, the MNCs were washed in fluorescence-activated cell sorter (FACS) buffer $(1 \times$ PBS, $2 \%$ fetal calf serum, $2 \%$ bovine serum albumin, and $0.01 \%$ $\mathrm{NaN}_{3}$ ) and stained with phycoerythrin- and allophycocyanin-labeled antibodies (Abs) against TLR2 and TLR4 (eBioscience), respectively, or matched isotype controls for $30 \mathrm{~min}$ at $4{ }^{\circ} \mathrm{C}$ in the dark. This was followed by a final wash and fixation in $1 \times \mathrm{BD}$ stabilizing fixative solution (BD Biosciences).

\section{pHrodo Labeling of SE}

For phagocytosis and intracellular cytokine experiments, SE bacteria were labeled with the $\mathrm{pH}$-sensitive fluorescent dye, pHrodo (Invitrogen, Carlsbad, CA). Labeled bacteria fluoresce brightly only in the phagosome at $\mathrm{pH}<4.0$. HKSE bacteria $\left(2.5 \times 10^{9}\right.$ per reaction $)$ were incubated for $1 \mathrm{~h}$ with $0.5 \mathrm{mmol} / \mathrm{l}$ of $\mathrm{pHrodo}$ succinimidyl ester and extensively washed to remove unbound dye, in accordance with the manufacturer's instructions. pHrodo-labeled SE bacteria were thoroughly dispersed before use by rapid vortexing for $30 \mathrm{~s}$ followed by $5 \mathrm{~min}$ in an ultrasonic water bath.

For the phagocytosis assay, MNCs were cultured for $1 \mathrm{~h}$ in the presence of pHrodo-labeled SE bacteria (100 bacteria/MNC) at $37^{\circ} \mathrm{C}$. After harvesting, the cells were washed and incubated in FACS buffer and permeabilized (BD Biosciences). The cells were incubated, and nonadherent bacteria were removed by washing twice with $2 \mathrm{ml}$ of ice-cold PBS (500 $g$, $5 \mathrm{~min}$ ) before fixing in $2 \%$ (vol/vol) formalin solution (in PBS) for flow cytometry.

For the intracellular cytokine assay, MNCs were cultured with pHrodo-labeled SE for $1 \mathrm{~h}$. The cells were incubated for a further $4 \mathrm{~h}$ at $37^{\circ} \mathrm{C}$ in the presence of $6 \mu \mathrm{g} / \mathrm{ml}$ of Brefeldin A (eBioscience) and then transferred to a polystyrene 96 -well plate. They were then washed twice with ice-cold PBS $(500 g, 5 \mathrm{~min})$ and immediately fixed using FACS-lyse solution (BD Biosciences) in accordance with the manufacturer's instructions. The cells were permeabilized using $1 \times$ permeabilization buffer for $10 \mathrm{~min}$ (BD Biosciences), washed, and resuspended in FACS buffer. They were then incubated with fluorescein isothiocyanate- or allophycocyanin-labeled antibodies against TNF- $\alpha$, IL-6 (eBioscience), or isotype controls for $30 \mathrm{~min}$ at $4^{\circ} \mathrm{C}$ in the dark, before two final washes and fixation in $1 \times$ stabilizing fixative solution (BD Biosciences).

To normalize for the potential effect of opsonization on phagocytosis, especially given that preterm infants are often hypocomplementemic (44), phagocytosis, intracellular killing, and intracellular cytokine assays were performed both with and without $10 \%$ baby rabbit complement (PelFreeze, Rogers, AR).

For all the assays, a minimum of 5,000 monocytes, identified by their forward/sideward scatter characteristics, were acquired uncompensated, using a FACSCalibur flow cytometer (BD Biosciences). BD CompBeads were used for all antibodies at acquisition to allow post hoc compensation, and data were analyzed using FlowJo software (Treestar, Ashland, OR ). For TLR expression analysis, the median fluorescence intensity of the isotype was subtracted from the median fluorescence intensity after staining with TLR-specific Abs. For the phagocytosis assay, the proportion of monocytes positive for SE ingestion was determined by setting a threshold marker of $1.5 \%$ of unstimulated monocytes. Phagocytosis was quantified from the median fluorescence intensity of the positive monocyte population. For intracellular cytokine staining, positively stained cells were identified by setting a threshold marker of $1.5 \%$ of isotype-labeled cells.

\section{Intracellular Killing Assay}

MNCs were cultured as described and inoculated with $10^{6} \mathrm{CFU} /$ $\mathrm{ml}$ of live SE bacteria for $30 \mathrm{~min}$ in the presence or absence of baby rabbit complement or cytochalasin D $(10 \mu \mathrm{g} / \mathrm{ml}$, Sigma). The cells were washed twice with ice-cold PBS $(500 \mathrm{~g}, 5 \mathrm{~min})$ to remove noninternalized bacteria and incubated for $2 \mathrm{~h}$ before being lysed by resuspension for $5 \mathrm{~min}$ in sterile water with $1 \%$ ethylene glycolate deoxycholate (Fluka AG, Buchs, Switzerland). The cell lysates were serially diluted, plated onto blood agar, and incubated at $37^{\circ} \mathrm{C} / 5 \%$ $\mathrm{CO}_{2}$. After $48 \mathrm{~h}$, viability was measured in terms of CFUs by manual counting. 


\section{Cell Signaling Studies}

Monocytes were isolated from whole MNCs using negative magnetic selection using a human monocyte enrichment kit without CD16 depletion (EasySep, Tullamarine, Australia). Purified monocytes $(>85 \%)$ were incubated with the following stimuli; pHrodo-labeled SE bacteria $\left(4 \times 10^{7} \mathrm{CFU} / \mathrm{ml}\right)$ with $10 \%$ baby rabbit complement, $10 \mathrm{ng} / \mathrm{ml} \mathrm{LPS} \mathrm{(Alexis,} \mathrm{Lausen,} \mathrm{Switzerland),} \mathrm{or} 100 \mathrm{ng} / \mathrm{ml} \mathrm{FSL-1}$ (Invivogen). The cells were harvested by transfer to $2 \mathrm{ml}$ of ice-cold PBS at 15, 30,60, 90, 120, and $150 \mathrm{~min}$. Unstimulated cells and those stimulated with LPS or FSL-1 were incubated only for $30 \mathrm{~min}$. After transfer, the cells were centrifuged and washed with ice-cold PBS and fixed in $1.5 \%$ (vol/vol) formaldehyde in PBS for $10 \mathrm{~min}$ at room temperature before permeabilization and further fixation with methanol for $10 \mathrm{~min}$ at $4^{\circ} \mathrm{C}$. The cells were washed twice with FACS buffer before staining with phycoerythrin-labeled anti-nuclear factor- $\kappa \mathrm{B}$ Abs, Alexa488-labeled anti-p38 Abs (BD Biosciences), and Alexa 647labeled anti-JNK Abs (Cell Signaling Technology, Danvers, MA), or matched fluorophore-labeled isotype control Abs, and analyzed on a FACSCalibur flow cytometer.

\section{Statistical Analysis}

Comparisons between groups were performed using the KruskalWallis test with Dunn's post-test, using Prism 5 for Mac (GraphPad, La Jolla, CA). For analysis of correlation, the Spearman $r$-test was used. Differences were considered significant at $P<0.05$.

\section{ACKNOWLEDGMENTS}

The authors thank Cristina Farrar, Anthony Keil, Peter Campbell, and David Atlas, Department of Microbiology, PathWest Laboratory Medicine WA, King Edward Memorial Hospital for Women, and Princess Margaret Hospital for Children, for their help with bacterial work. The support of Susan Prescott in recruitment of the study populations is gratefully acknowledged. The authors thank all participating families. They also thank the Vaccine Trials Group for their clinical and scientific contributions, and the midwifery, obstetric, and neonatal staff at King Edward Memorial Hospital, for their assistance in the completion of this study.

\section{STATEMENT OF FINANCIAL SUPPORT}

This study was supported by Princess Margaret Hospital, Women's and Infants' Research Foundation (WA), Clive and Vera Ramaciotti Medical Research Foundation, University of Western Australia, Rebecca Cooper Medical Research Foundation, Channel 7 Telethon, European Society for Paediatric Infectious Diseases, and the National Health and Medical Research Council (project grant 513847), Australia. T.S. was supported by the Deutsche Forschungsgemeinschaft (STR1022/1-1) and by an international postgraduate research scholarship of the University of Western Australia. A.C. is supported by a BrightSpark Foundation WA Fellowship. D.B. is supported by a National Health and Medical Research Council Career Development Award. O.L.'s laboratory is supported by National Institutes of Health RO1 Al067353-01A1, an RO1 American Recovery and Re-investment Act administrative supplement (R01Al067353-05S1), and by Global Health grant OPPGH5284 from The Bill \& Melinda Gates Foundation. O.L. is a recipient of a Harvard-Australia Fellowship. This research was supported by the Victorian Government's Operational Infrastructure Support Program.

Disclosure: The authors have no conflicts of interest.

\section{REFERENCES}

1. Carrieri MP, Stolfi I, Moro ML. Intercenter variability and time of onset: two crucial issues in the analysis of risk factors for nosocomial sepsis. Pediatr Infect Dis J 2003;22:599-609.

2. Vergnano S, Menson E, Kennea N, et al. Neonatal infections in England: the NeonIN surveillance network. Arch Dis Child Fetal Neonatal Ed 2011;96:F9-14.

3. Weisman LE. Coagulase-negative staphylococcal disease: emerging therapies for the neonatal and pediatric patient. Curr Opin Infect Dis 2004;17:237-41.

4. Isaacs D. A ten year, multicentre study of coagulase negative staphylococcal infections in Australasian neonatal units. Arch Dis Child Fetal Neonatal Ed 2003;88:F89-93.
5. Healy CM, Palazzi DL, Edwards MS, Campbell JR, Baker CJ. Features of invasive staphylococcal disease in neonates. Pediatrics 2004;114:953-61.

6. Källman J, Kihlström E, Sjöberg L, Schollin J. Increase of staphylococci in neonatal septicaemia: a fourteen-year study. Acta Paediatr 1997;86:533-8.

7. Stoll BJ, Hansen N, Fanaroff AA, et al. Late-onset sepsis in very low birth weight neonates: the experience of the NICHD Neonatal Research Network. Pediatrics 2002;110(2 Pt 1):285-91.

8. Gray JE, Richardson DK, McCormick MC, Goldmann DA. Coagulasenegative staphylococcal bacteremia among very low birth weight infants: relation to admission illness severity, resource use, and outcome. Pediatrics 1995;95:225-30.

9. Payne NR, Carpenter JH, Badger GJ, Horbar JD, Rogowski J. Marginal increase in cost and excess length of stay associated with nosocomial bloodstream infections in surviving very low birth weight infants. Pediatrics 2004;114:348-55.

10. Mittendorf R, Roizen N, Moawad A, Khoshnood B, Lee KS. Association between cerebral palsy and coagulase-negative staphylococci. Lancet 1999;354:1875-6.

11. Gonzalez A, Sosenko IR, Chandar J, Hummler H, Claure N, Bancalari E. Influence of infection on patent ductus arteriosus and chronic lung disease in premature infants weighing 1000 grams or less. J Pediatr 1996;128:470-8.

12. Liljedahl M, Bodin L, Schollin J. Coagulase-negative staphylococcal sepsis as a predictor of bronchopulmonary dysplasia. Acta Paediatr 2004;93:211-5.

13. Wynn JL, Levy O. Role of innate host defenses in susceptibility to earlyonset neonatal sepsis. Clin Perinatol 2010;37:307-37.

14. Strunk T, Richmond P, Simmer K, Currie A, Levy O, Burgner D. Neonatal immune responses to coagulase-negative staphylococci. Curr Opin Infect Dis 2007;20:370-5.

15. Cheung GY, Otto M. Understanding the significance of Staphylococcus epidermidis bacteremia in babies and children. Curr Opin Infect Dis 2010;23:208-16.

16. Kenzel S, Henneke P. The innate immune system and its relevance to neonatal sepsis. Curr Opin Infect Dis 2006;19:264-70.

17. Currie AJ, Curtis S, Strunk T, et al. Preterm infants have deficient monocyte and lymphocyte cytokine responses to group B streptococcus. Infect Immun 2011;79:1588-96.

18. Keyworth N, Millar MR, Holland KT. Development of cutaneous microflora in premature neonates. Arch Dis Child 1992;67(7 Spec No): 797-801.

19. Härtel C, Osthues I, Rupp J, et al. Characterisation of the host inflammatory response to Staphylococcus epidermidis in neonatal whole blood. Arch Dis Child Fetal Neonatal Ed 2008;93:F140-5.

20. Watanabe I, Ichiki M, Shiratsuchi A, Nakanishi Y. TLR2-mediated survival of Staphylococcus aureus in macrophages: a novel bacterial strategy against host innate immunity. J Immunol 2007;178:4917-25.

21. Carr JA, Hodgman JE, Freedman RI, Levan NE. Relationship between toxic erythema and infant maturity. Am J Dis Child 1966;112:129-34.

22. Hidano A, Purwoko R, Jitsukawa K. Statistical survey of skin changes in Japanese neonates. Pediatr Dermatol 1986;3:140-4.

23. Marchini G, Nelson A, Edner J, Lonne-Rahm S, Stavréus-Evers A, Hultenby $\mathrm{K}$. Erythema toxicum neonatorum is an innate immune response to commensal microbes penetrated into the skin of the newborn infant. Pediatr Res 2005;58:613-6.

24. Angelone DF, Wessels MR, Coughlin M, et al. Innate immunity of the human newborn is polarized toward a high ratio of IL-6/TNF-alpha production in vitro and in vivo. Pediatr Res 2006;60:205-9.

25. Speer CP, Gahr M, Wieland M, Eber S. Phagocytosis-associated functions in neonatal monocyte-derived macrophages. Pediatr Res 1988; 24:213-6.

26. Strunk T, Temming P, Gembruch U, Reiss I, Bucsky P, Schultz C. Differential maturation of the innate immune response in human fetuses. Pediatr Res 2004;56:219-26.

27. Speer CP, Ambruso DR, Grimsley J, Johnston RB Jr. Oxidative metabolism in cord blood monocytes and monocyte-derived macrophages. Infect Immun 1985;50:919-21. 
28. Speer CP, Wieland M, Ulbrich R, Gahr M. Phagocytic activities in neonatal monocytes. Eur J Pediatr 1986;145:418-21.

29. Conly ME, Speert DP. Human neonatal monocyte-derived macrophages and neutrophils exhibit normal nonopsonic and opsonic receptor-mediated phagocytosis and superoxide anion production. Biol Neonate 1991;60: 361-6.

30. Power Coombs MR, Belderbos ME, Gallington LC, Bont L, Levy O. Adenosine modulates Toll-like receptor function: basic mechanisms and translational opportunities. Expert Rev Anti Infect Ther 2011;9:261-9.

31. Pepys MB, Hirschfield GM. C-reactive protein: a critical update. J Clin Invest 2003;111:1805-12.

32. Klingenberg C, Aarag E, Rønnestad A, et al. Coagulase-negative staphylococcal sepsis in neonates. Association between antibiotic resistance, biofilm formation and the host inflammatory response. Pediatr Infect Dis J 2005;24:817-22.

33. Strunk T, Power Coombs MR, Currie AJ, et al. TLR2 mediates recognition of live Staphylococcus epidermidis and clearance of bacteremia. PLoS ONE 2010;5:e10111.

34. Akira S, Uematsu S, Takeuchi O. Pathogen recognition and innate immunity. Cell 2006;124:783-801.

35. Levy O, Zarember KA, Roy RM, Cywes C, Godowski PJ, Wessels MR. Selective impairment of TLR-mediated innate immunity in human newborns: neonatal blood plasma reduces monocyte TNF-alpha induction by bacterial lipopeptides, lipopolysaccharide, and imiquimod, but preserves the response to R-848. J Immunol 2004;173:4627-34.
36. Förster-Waldl E, Sadeghi K, Tamandl D, et al. Monocyte toll-like receptor 4 expression and LPS-induced cytokine production increase during gestational aging. Pediatr Res 2005;58:121-4.

37. Strunk T, Doherty D, Richmond P, et al. Reduced levels of antimicrobial proteins and peptides in human cord blood plasma. Arch Dis Child Fetal Neonatal Ed 2009;94:F230-1.

38. Redline RW. Placental inflammation. Semin Neonatol 2004;9:265-74.

39. Stoll BJ, Hansen N, Fanaroff AA, et al. Late-onset sepsis in very low birth weight neonates: the experience of the NICHD Neonatal Research Network. Pediatrics 2002;110(2 Pt 1):285-91.

40. Macaubas C, Sly PD, Burton P, et al. Regulation of T-helper cell responses to inhalant allergen during early childhood. Clin Exp Allergy 1999;29:1223-31.

41. Mack D, Siemssen N, Laufs R. Parallel induction by glucose of adherence and a polysaccharide antigen specific for plastic-adherent Staphylococcus epidermidis: evidence for functional relation to intercellular adhesion. Infect Immun 1992;60:2048-57.

42. Rowe J, Heaton T, Kusel M, et al. High IFN-gamma production by CD8+ $\mathrm{T}$ cells and early sensitization among infants at high risk of atopy. J Allergy Clin Immunol 2004;113:710-6.

43. Schmittgen TD, Livak KJ. Analyzing real-time PCR data by the comparative C(T) method. Nat Protoc 2008;3:1101-8.

44. Schutze GE, Hall MA, Baker CJ, Edwards MS. Role of neutrophil receptors in opsonophagocytosis of coagulase-negative staphylococci. Infect Immun 1991;59:2573-8. 